\title{
Mechanosensitivity of nicotinic receptors
}

\author{
N. Clara Pan $\cdot$ Jin Jin Ma $\cdot$ H. Benjamin Peng
}

Received: 12 April 2012 / Revised: 8 June 2012 / Accepted: 12 June 2012 / Published online: 26 June 2012

(C) The Author(s) 2012. This article is published with open access at Springerlink.com

\begin{abstract}
Nicotinic acetylcholine receptors (nAChRs) are heteropentameric ligand-gated ion channels that mediate excitatory neurotransmission at the neuromuscular junction (NMJ) and other peripheral and central synapses. At the $\mathrm{NMJ}$, acetylcholine receptors (AChRs) are constantly exposed to mechanical stress resulting from muscle contraction. It is therefore of interest to understand if their function is influenced by mechanical stimuli. In this study, patch-clamp recordings showed that $\mathrm{AChR}$ channel activity was enhanced upon membrane stretching in both cultured Xenopus muscle cells and $\mathrm{C} 2 \mathrm{C} 12$ myotubes. To examine how this property is physiologically regulated, effects of membrane-intrinsic and membrane-extrinsic factors on AChRs expressed in HEK293T cells were studied. As in muscle cells, AChR single channel currents recorded under cell-attached configuration were significantly increased - without change in current amplitude - when negative pressure was applied through the patch pipette. GsMTx-4, a peptide toxin that blocks mechanically activated cation channels, inhibited this effect on AChRs. The mechanosensitivity decreased when cells were treated with $\mathrm{M} \beta \mathrm{CD}$, latrunculin $\mathrm{A}$ or cytochalasin $\mathrm{D}$, but increased when exposed to lysophosphatidylcholine,
\end{abstract}

Electronic supplementary material The online version of this article (doi:10.1007/s00424-012-1132-9) contains supplementary material, which is available to authorized users.

N. C. Pan $\cdot$ J. J. Ma $\cdot$ H. B. Peng $(\bowtie)$

Division of Life Science,

State Key Laboratory of Molecular Neuroscience,

The Hong Kong University of Science and Technology,

Clear Water Bay,

Kowloon, Hong Kong

e-mail: penghb@ust.hk

Present Address:

N. C. Pan

Department of Neurobiology, Beijing Institute for Neuroscience,

The Capital Medical University,

Beijing, China 100069 indicating contributions from both membrane lipids and the cytoskeleton. Rapsyn, which binds to AChRs and mediates their cytoskeletal interaction in muscle, suppressed AChR mechanosensitivity when co-expressed in HEK293T cells, but this influence of rapsyn was impaired following the deletion of rapsyn's AChR-binding domain or upon cytoskeletal disruption by cytochalasin $\mathrm{D}$. These results suggest a mechanism for regulating AChR's mechanosensitivity through its cytoskeletal linkage via rapsyn, which may serve to protect the receptors and sarcolemmal integrity under high mechanical stress encountered by the NMJ.

Keywords Acetylcholine receptor · Mechanosensitivity · Rapsyn $\cdot$ Neuromuscular junction
Abbreviations
AChR acetylcholine receptor
BTX $\alpha$-bungarotoxin
CD cytochalasin D
LtnA latrunculin A
LPC lysophosphatidylcholine
$\mathrm{M} \beta \mathrm{CD}$ methyl-beta-cyclodextrin
MSC mechanosensitive channel
NMJ neuromuscular junction
R-BTX rhodamine-conjugated $\alpha$-bungarotoxin

\section{Introduction}

Ion channels are essential regulators of cellular functions. They are broadly categorized as voltage- or ligand-gated, depending on whether they are activated by membrane potential changes or by ligand binding. In addition, mechanosensitive channels (MSCs) activated or inhibited by membrane stretch are widely distributed in many types of cells $[2,22$, 24]. MSCs mediate a variety of functions, ranging from the 
highly specialized mechanical transduction mediated by channels at the tip of stereocilia in vertebrate hair cells $[20,40,48]$, to the general maintenance of membrane integrity as in the case of MscL/S channels in the prokaryotic membrane [24]. MSCs are also abundantly expressed in skeletal muscle [13, $14,19]$ where they are involved in the maintenance of sarcolemmal integrity; their increased activity in dystrophic muscle is correlated with muscle pathology.

Also highly expressed in vertebrate skeletal muscle are the ligand-gated nicotinic acetylcholine receptors (AChRs) that mediate synaptic transmission at the neuromuscular junction (NMJ). Each AChR is a pentamer composed of two $\alpha$ subunits and one each of $\beta, \gamma$ and $\delta$ subunits in embryonic muscle, with $\gamma$ being replaced by an $\varepsilon$ subunit in the adult [29]. The five subunits together form a central pore for cation permeation upon ligand binding to the $\alpha$ subunits. At the postsynaptic membrane, AChRs are clustered to a density of $\sim 10,000$ per $\mu \mathrm{m}^{2}$ [12]. This AChR-centered postsynaptic apparatus is maintained throughout life and is essential for efficacious excitation-contraction coupling at the NMJ. In patients suffering from the acquired autoimmune disease myasthenia gravis, the high AChR site density is impaired as a result of autoantibody-induced increase in AChR turnover and degradation [27]. AChR subunit mutations, on the other hand, cause congenital myasthenic syndrome [11]. Thus, the stability and function of AChRs are important for the NMJ's integrity.

Being membrane-intrinsic molecules, AChRs, like MSCs, are subject to mechanical stress arising from muscular contraction. It is thus of interest to understand how AChRs cope with this stress to perform their physiological functions reliably and also if and how their gating properties are affected by shear force applied to the membrane. AChRs are aggregated and stabilized at the NMJ via a cytoskeleton-dependent mechanism which is mediated by rapsyn, a $43-\mathrm{kD}$ protein that associates with AChR subunits [4] and whose targeted deletion abolishes AChR clustering in muscle [16]. Therefore, rapsyn may also be a player in AChR's response to mechanical stress. In this study, we examined AChR's mechanosensitivity in its natural muscle cell environment and in heterologous cells expressing this receptor as an exogenous protein. We moreover tested the influence of rapsyn on this property. We report that mechanical stretching of the membrane enhanced ligand activation of AChRs and that rapsyn suppressed AChR's mechanosensitivity.

\section{Methods}

\section{Ethical approval}

The use of animals in this study was approved by the Animal Ethics Committee of the Hong Kong University of Science and Technology.

\section{Cell cultures}

Myotomal muscle cells were cultured from Xenopus embryos as previously described [34]. Electrophysiological experiments were performed in cultures 1-2 days old. HEK293T cells were cultured in DMEM supplemented with $10 \%$ fetal bovine serum (FBS) and incubated at $37{ }^{\circ} \mathrm{C}$ in $5 \% \mathrm{CO}_{2}$, and 1 day before transfection, the cells were transferred to 24-well plates. Transfection was carried out with cDNAs encoding AChR's four subunits and green fluorescent protein (GFP) at the ratio $\alpha / \beta / \gamma / \delta / \mathrm{GFP}=0.6: 0.3: 0.3: 0.3: 0.1$ (micrograms) per well. For co-transfection of AChR and rapsyn, $0.3 \mu \mathrm{g}$ rapsynGFP cDNA per well was additionally included. At $90 \%$ confluence, cells were transiently transfected using Lipofectamine2000 (Invitrogen, Carlsbad, CA). Electrophysiological experiments were performed 1-2 days after transfection. Cells from mouse $\mathrm{C} 2 \mathrm{C} 12$ skeletal muscle line (obtained from American Type Culture Collection, Manassas, VA) were cultured in DMEM supplemented with $20 \% \mathrm{FBS}$ at $37^{\circ} \mathrm{C}$ in $5 \%$ $\mathrm{CO}_{2}$. Myoblasts were induced to differentiate into myotubes by changing the medium to DMEM containing $2 \%$ horse serum. Electrophysiological experiments were performed on myotubes 4-5 days after changing to this differentiation medium.

cDNAs and other reagents

Constructs encoding mouse AChR $\alpha, \beta, \gamma$ and $\delta$ subunits were generously provided by Dr. Stanley C. Froehner (University of Washington, Seattle). AChR $\varepsilon$ subunit cDNA was a kind gift from Dr. Veit Witzemann (Max Planck Institute for Medical Research, Heidelberg, Germany) and rapsyn cDNA kindly provided by Dr. Jean Cartaud (Institut Jacques Monod, Universités Paris). A rapsyn construct with deletion of the coiled coil domain $(\Delta 297-331)$ was generated by PCR. Both wild-type and mutant rapsyn were tagged at the C-terminus with enhanced GFP (EGFP) by inserting them into pEGFP-N1 plasmid (Clonetech, Madison, WI).

The following reagents were from commercial sources: $\alpha$-bungarotoxin (BTX) and latrunculin A (LtnA) from Molecular Probes/Invitrogen (Eugene, Oregon, USA), GsMTx4 from Peptide Institute, Inc. (Osaka, Japan), and cytochalasin $\mathrm{D}$, methyl-beta-cyclodextrin $(\mathrm{M} \beta \mathrm{CD})$, and lysophosphatidylcholine (LPC) from Sigma (St. Louis, MO, USA).

Patch-clamp recording

In most cases, the cell-attached mode was used in singlechannel recordings. All experiments were at room temperature. The recording was conducted with Axopatch 200B patch-clamp amplifier with associated software (Axon Instruments/Molecular Devices, Union City, CA). Currents were typically digitized at $10 \mathrm{kHz}$, macroscopic records 
were filtered at $2 \mathrm{kHz}$. Data were analyzed with Clampfit (version 10.0; Axon Instruments) and Sigmaplot (Systat Software, Inc., Chicago, IL) software. All data are presented as mean \pm SEM.

For recording from Xenopus muscle cells, Ringer solution $\left(110 \mathrm{mM} \mathrm{NaCl}, 1 \mathrm{mM} \mathrm{KCl}, 1.8 \mathrm{mM} \mathrm{CaCl}_{2}\right.$, and $8 \mathrm{mM}$ HEPES, pH 7.4) was used in the pipette and bath. For recording from mammalian cells $(\mathrm{C} 2 \mathrm{C} 12$ myotubes and HEK293T cells), the pipette solution contained $150 \mathrm{mM}$ $\mathrm{KCl}, 2.5 \mathrm{mM} \mathrm{MgCl}_{2}, 0.2 \mathrm{mM}$ EGTA, and $10 \mathrm{mM}$ HEPES, $\mathrm{pH} 7.4$, and the bath solution contained $150 \mathrm{mM} \mathrm{NaCl}$, $5 \mathrm{mM} \mathrm{KCl}, 2 \mathrm{mM} \mathrm{CaCl}_{2}, 1 \mathrm{mM} \mathrm{MgCl}, 10 \mathrm{mM}$ glucose, and $10 \mathrm{mM}$ HEPES, $\mathrm{pH}$ 7.4. For inside-out patch-clamp experiments on HEK293T cells, the first solution containing high $\mathrm{KCl}$ was used in the pipette and in the bath.

To stretch the membrane patch while recording, negative pressure was manually applied with a $1-\mathrm{mL}$ syringe attached to the pipette via silicone tubing and a three-way stopcock. Pressures were monitored with a pressure gauge (PM01R, World Precision Instruments, Sarasota, FL) and displayed by Axon pClamp 10 software. The pressure trace is shown in figures together with current recordings with the baseline showing the atmospheric pressure (negative pressure $=$ $0 \mathrm{mmHg}$ ) and downward steps showing the magnitude of the negative pressure. A scale for the negative pressure is included in each figure where current recordings are shown. The patch diameter was approximately $1 \mu \mathrm{m}$. The value of NPo was calculated by using "single-channel search" function in the Clampfit software. For data obtained from the same cell, paired $t$ test was used whereas unpaired $t$ test was adopted for analyzing data collected from a group of cells.

\section{Results}

Mechanosensitivity of AChRs in cultured skeletal muscle cells

Acetylcholine-induced single-channel currents were recorded from cultured Xenopus myotomal muscle cells using the cellattached patch-clamp technique. To study the mechanosensitive property of these receptor channels, the membrane patch under recording was stretched by negative pressure applied through the pipette by suction. The duration of the negative pressure application was about $10 \mathrm{~s}$ for each step. After each application, the negative pressure was released to allow cell recovery before the next step was applied. Membrane stretching caused by negative pressure as low as $-10 \mathrm{mmHg}$ resulted in a striking increase in AChR single channel opening activated by $200 \mathrm{nM}$ ACh in the pipette (Fig. 1a). This was accompanied by an increase in the occurrence of multiple channel activation and prolongation of the mean open time. Channel opening returned to normal state after the negative pressure was released. To quantify this effect, we calculated the channel activity, NPo (Fig. 1b), and the difference before and under negative pressure application, $\Delta \mathrm{NPo}$ (Fig. 1c). In a strength-dependent and reversible manner, negative pressure enhanced ligand-activated AChR opening.

In these muscle cells, single channel currents displayed two distinct amplitudes of 6 and $8 \mathrm{pA}$, corresponding to AChRs containing $\gamma$ and $\varepsilon$ subunits, respectively [26]. The resting membrane potential was about $-70 \mathrm{mV}$. Together with the pipette holding potential of $+70 \mathrm{mV}$, a calculated net membrane potential of $-140 \mathrm{mV}$ was imposed on the patch membrane. This allowed us to deduce the single-channel conductance of $\gamma$ - and $\varepsilon$-containing AChRs at 43 and $57 \mathrm{pS}$, respectively. Although membrane stretching increased channel activity, the AChR single channel currents were not affected (Fig. 1a; described in more detail below).

To determine if this mechanosensitive property was unique to AChRs in Xenopus muscle cells, a similar study was carried out on $\mathrm{C} 2 \mathrm{C} 12$ myotubes. AChRs in these cells also exhibited mechanosensitivity in response to membrane stretching by negative pressure applied through the patchclamp pipette (Fig. 1d-f). This increase in channel opening was not as large as that in Xenopus primary muscle cultures. These mechanosensitive, ACh-activated channels were identified unambiguously as nicotinic receptors by the finding that their currents were abolished by the nicotinic antagonist $\alpha$-bungarotoxin (Supplemental Fig. S1a).

\section{AChR mechanosensitivity in heterologous cells}

To further characterize the mechanosensitivity of nicotinic receptors, we introduced AChRs into HEK293T cells that do not express these receptors endogenously. Transfection of cDNAs encoding muscle-type AChR subunits $\alpha, \beta, \gamma$, and $\delta$ into these cells led to the expression of AChRs at the cell surface, as shown by the appearance of ACh-induced currents (Fig. 2a and Supplemental Fig. S1b). The mechanosensitivity of these exogenous AChRs was readily apparent (Figs. 2a, b), and at negative pressures over $-60 \mathrm{mmHg}$, membrane stretching more than doubled the channel opening with respect to control (Fig. 2c). However, while channel activity was dramatically enhanced, the amplitude of single-channel current was not altered (Fig. 2d). This is also shown in the histogram of single channel currents in Fig. 2e. The net ACh-induced current amplitude after baseline subtraction was about $5.1 \mathrm{pA}$ for all negative pressure levels tested (Fig. 2e). In these experiments, a pipette holding potential of $+70 \mathrm{mV}$ was used in all recordings. Since the resting potential of HEK293 cells was at $-40 \mathrm{mV}$ [44], the calculated conductance of AChR single channel was $\sim 46 \mathrm{pS}$ under the driving force of $-110 \mathrm{mV}$ net membrane potential. This value was consistent with that of muscle $\gamma$-containing AChRs as described previously. 

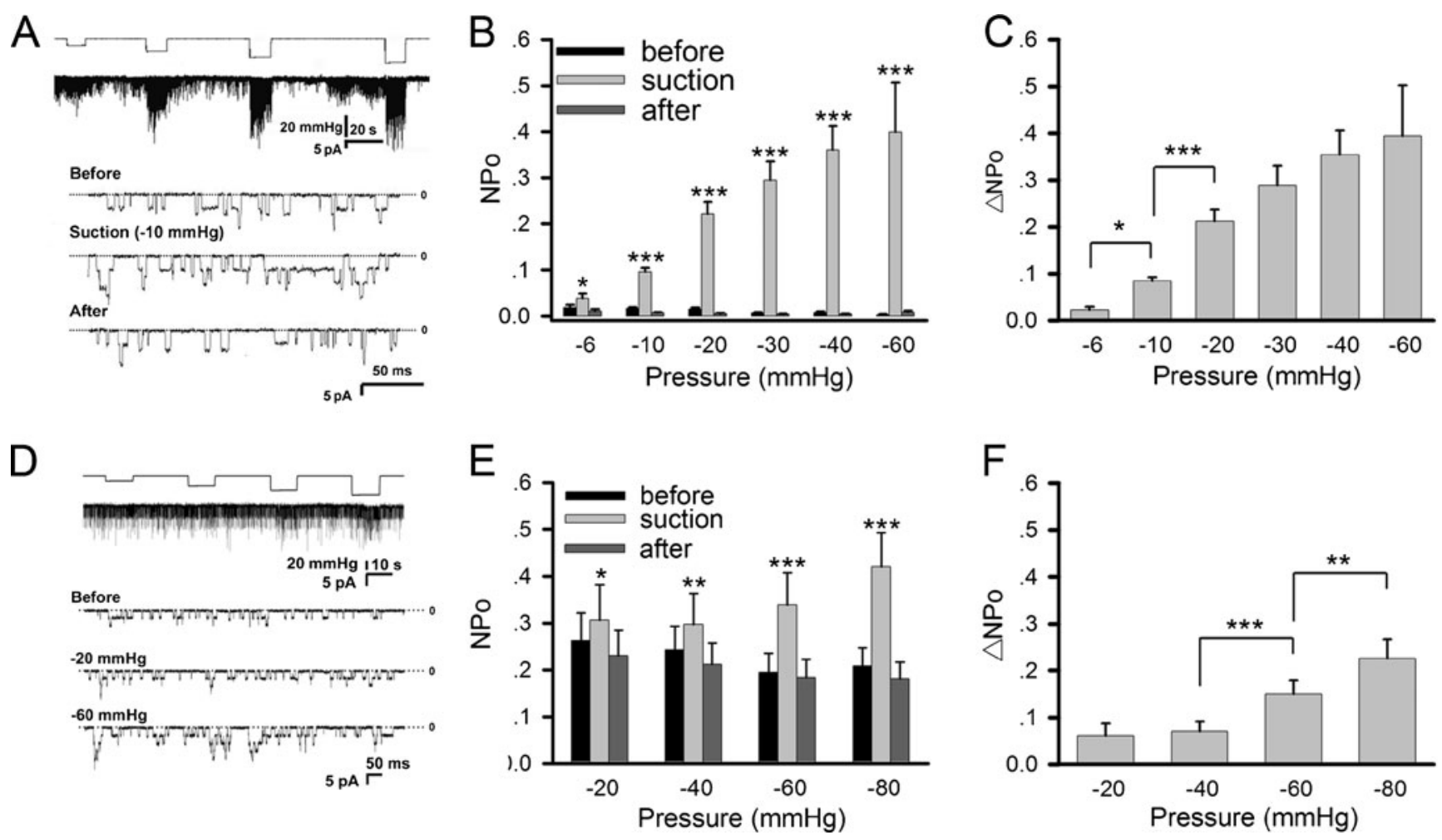

Fig. 1 Mechanosensitivity of AChRs in muscle cells. AChR activity was studied in cultured Xenopus myotomal muscle cells (a-c) and C2C12 myotubes (d-f). a Sample traces of ACh-induced singlechannel currents from Xenopus muscle cells recorded with the patchclamp method under negative pipette pressure of different magnitudes. Pipette ACh concentration $=0.2 \mu \mathrm{M}$, holding potential $=+70 \mathrm{mV}$, cellattached mode. b Channel activity NPo and $\mathbf{c}$ its difference $\triangle \mathrm{NPo}$ under different negative pressures. For the NPo plot, values before (black), during (gray), and after (dark gray) negative pressure application are shown. Data are mean \pm SEM, number of patches $n=9,91,46$,

As another test to verify the mechanosensitivity of AChR channels, we used GsMTx-4, a peptide toxin isolated from the venom of the Chilean rose tarantula (Grammostola spatulata) that blocks stretch-activated cation channels [43]. Inclusion of this toxin at $1 \mu \mathrm{M}$ in the ACh-containing pipette solution potently inhibited the change in AChR channel activity $(\triangle \mathrm{NPo})$ triggered by membrane stretching, an effect especially noticeable at high negative pressures (Fig. 3a).

As noted above, the AChR subunit makeup changes during development from the embryonic type $\alpha(2) \beta \delta \gamma$ to adult type $\alpha(2) \beta \delta \varepsilon$. The foregoing results from heterologous cells were obtained using the embryonic AChR subunit composition. Recording was thus also performed on HEK293T cells expressing the adult combination. Compared to $\gamma$-containing channels, the $\varepsilon$ containing ones have a shorter single-channel opening time and higher current amplitude. Nevertheless, they also clearly exhibited mechanosensitivity in response to negative pipette pressure (Supplemental Fig. S2).
$46,44,18$ for negative pressures of $-6,-10,-20,-30,-40,-60 \mathrm{mmHg}$, respectively. d AChR single channel currents recorded from $\mathrm{C} 2 \mathrm{C} 12$ myotubes under different negative pressures. ACh concentration= $0.5 \mu \mathrm{M}$. e NPo values before (black), during (gray), and after (dark gray) negative pressure application. $\mathbf{f} \Delta \mathrm{NPo}$ data from $\mathrm{C} 2 \mathrm{C} 12$ cells. Data from 20 patches at each negative pressure were pooled. Statistics: ${ }^{*} p<0.05$; $*^{*} p<0.01 ; * * * p<0.001$ (Student's paired $t$ test). For NPo plots, comparisons were made between values obtained during and before negative pressure application

Effects of membrane and cytoskeletal perturbation on AChR's mechanosensitivity

Previous studies have implicated both the membrane lipid bilayer and the cytoskeleton as determinants in ion channels' mechanosensitivity. To understand the cell membrane's influence on AChR's mechanosensitivity, the membrane lipid content was perturbed by treating AChR-expressing HEK293T cells with the cholesteroldepleting agent methyl- $\beta$-cyclodextrin $(\mathrm{M} \beta \mathrm{CD})[8,31]$. Following incubation with $10 \mathrm{mM} \mathrm{M} \beta \mathrm{CD}$ for $20 \mathrm{~min}$, cell-attached single-channel recording showed that AChRs became much less sensitive to membrane stretch when the negative pressure was in the range of -60 to $-80 \mathrm{mmHg}$ (Fig. 3a). In the absence of membrane stretching, $\mathrm{M} \beta \mathrm{CD}$ did not affect the gating of AChRs.

Previous studies have shown that the gating property of bacterial mechanosensitive channels MscL and MscS can be profoundly modified by the intercalation of the conical phospholipid lysophosphatidylcholine (LPC) 
Fig. 2 Mechanosensitivity of AChRs exogenously expressed in HEK293T cells. Cells were transfected with AChR subunits $\alpha, \beta, \delta$, and $\gamma$. a Sample traces of ACh-induced currents under different negative pressures. Included in the pipette was $0.5 \mu \mathrm{M}$ ACh. b Channel activity NPo and $\mathbf{c}$ its difference $\triangle$ NPo under different negative pressure levels; the former shows values before (black), during (gray), and after (dark gray) negative pressure application; $n=26,24,22,10$ patches for $-20,-40,-60$, $-80 \mathrm{mmHg}$, respectively. Symbols denoting statistical significance are the same as in Fig. 1. d Mean amplitudes of single channel currents at different negative pressures. These values were calculated from allpoints amplitude histograms as shown in (e), taking the difference between the first and second peak as the mean singlechannel AChR current amplitude
A

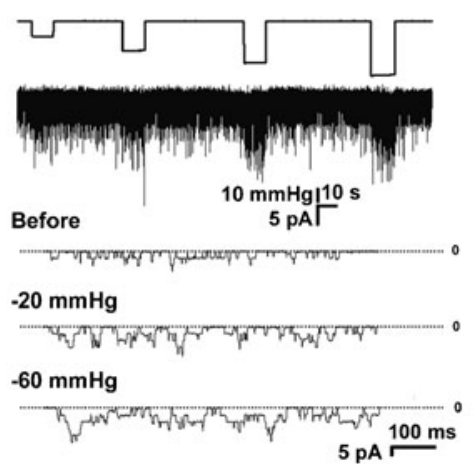

B

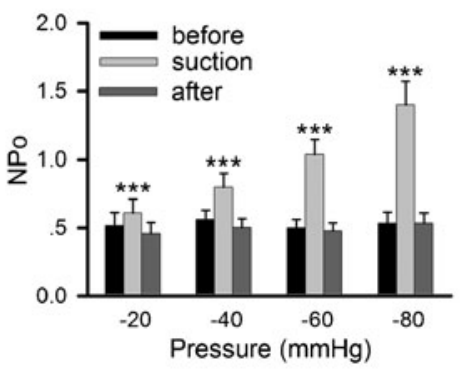

C

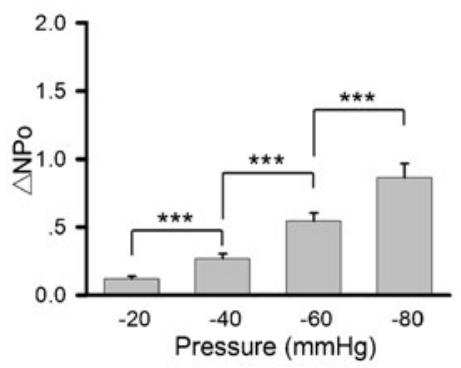

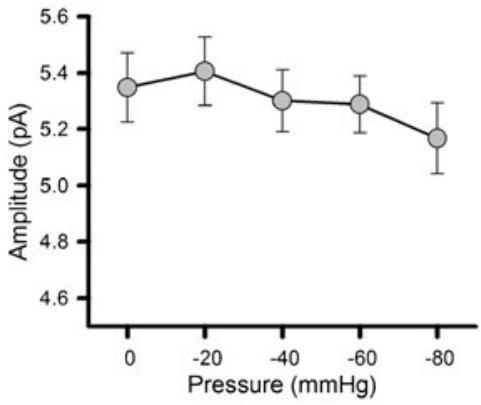

$E$

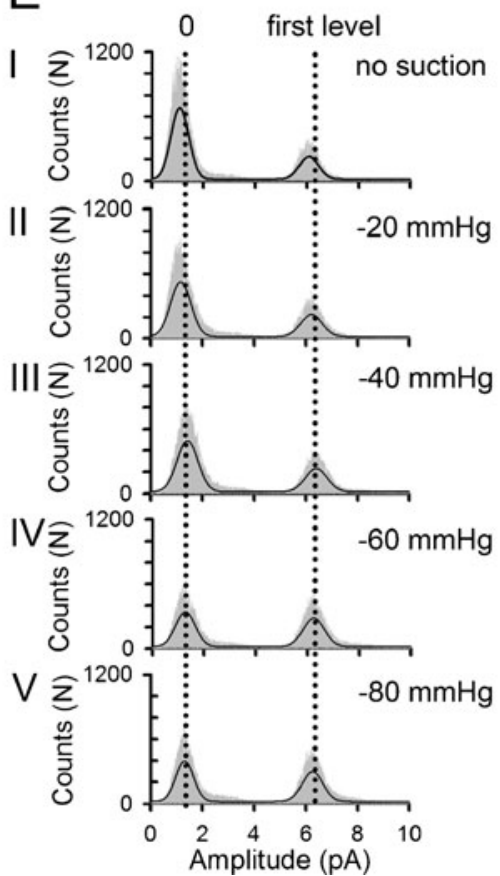

$[35,46]$. LPC added to one side of the lipid bilayer causes an increase in MscL's mechanosensitivity. To further understand the involvement of the membrane environment on AChR's mechanosensitivity, we preincubated receptor-expressing HEK293 cells with $5 \mu \mathrm{M}$ LPC for $10 \mathrm{~min}$ according to previously published method [1] and then recorded ACh-induced single-channel currents. As shown in Fig. 4, the increase in ligand-induced channel activity due to negative pressure was significantly enhanced, especially at higher pressures, as a result of LPC application.

The action of the cytoskeleton was studied by disrupting F-actin assembly and stability with latrunculin A (LtnA) and cytochalasin D. LtnA, isolated from the Red Sea sponge Latrunculia magnifica, interferes with actin polymerization through binding and sequestering monomeric G-actin [9, 42]. Cytochalasin D, a fungal metabolite, binds to nuclei and filaments of F-actin and blocks the incorporation of G-actin [7]. Both agents also destabilize and depolymerize F-actin. Pre-incubation of HEK293T cells expressing AChRs with either $2 \mu \mathrm{M}$ cytochalasin $\mathrm{D}$ for $30 \mathrm{~min}$ or $5 \mu \mathrm{M} \operatorname{LtnA}$ for $2 \mathrm{~h}$ caused significant reduction in the receptors' sensitivity to membrane stretch at negative pressures of $-60 \mathrm{mmHg}$ and above (Fig. 3a). However, these actin depolymerizing agents did not affect AChR gating in the absence of membrane stretching.

The importance of the intact cytoskeleton was further probed by recording from inside-out membrane patches. In this configuration, the pipette-associated membrane patch is detached from the cell and (therefore) its underlying cytoskeleton, giving it the "inside-out" configuration. Negative pressure was applied to the isolated membrane to cause its stretching and concave distortion in the same way as in an intact cell. In sharp contrast to what was seen in cell-attached recordings, AChRs' mechanosensitivity in inside-out patches was almost absent at $-40 \mathrm{mmHg}$ negative pipette pressure and weak at $-60 \mathrm{mmHg}$ (Fig. 3b-e). These data suggest that the mechanosensitivity of AChRs is conveyed through both the lipid bilayer and the cytoskeleton. 
Fig. 3 Analyses of AChR mechanosensitivity in HEK293T cells. a Effects of different pharmacological agents on $\triangle$ NPo. Cell-attached single-channel recording was conducted. GsMTx-4 (1 $\mu \mathrm{M})$, a mechanosensitive channel blocker, was included in the recording pipette. Cells were incubated before recordings for $20 \mathrm{~min}$ in $10 \mathrm{mM} \mathrm{M} \beta \mathrm{CD}$, a cholesterol-depleting agent; $30 \mathrm{~min}$ in $2 \mu \mathrm{M}$ cytochalasin $\mathrm{D}$, an F-actin inhibitor; or for $2 \mathrm{~h}$ in $5 \mu \mathrm{M}$ latrunculin $\mathrm{A}$, another $\mathrm{F}$ actin inhibitor. Number of patches recorded: 26 (control), 26 (GsMTx-4), 19 (MßCD), 29 (cytochalasin D), and 19 (latrunculin A). b-e Comparison of on-cell and inside-out recordings. Data are mean \pm SEM based on $n=10$ patches (for each negative pressure). The same membrane patch was first recorded on-cell and then detached from the cell for inside-out measurement with a pipette holding potential of $+70 \mathrm{mV}$ and $0.5 \mu \mathrm{M}$ ACh. ${ }^{*} p<0.05 ; * * p<0.01$; $* * * p<0.001$
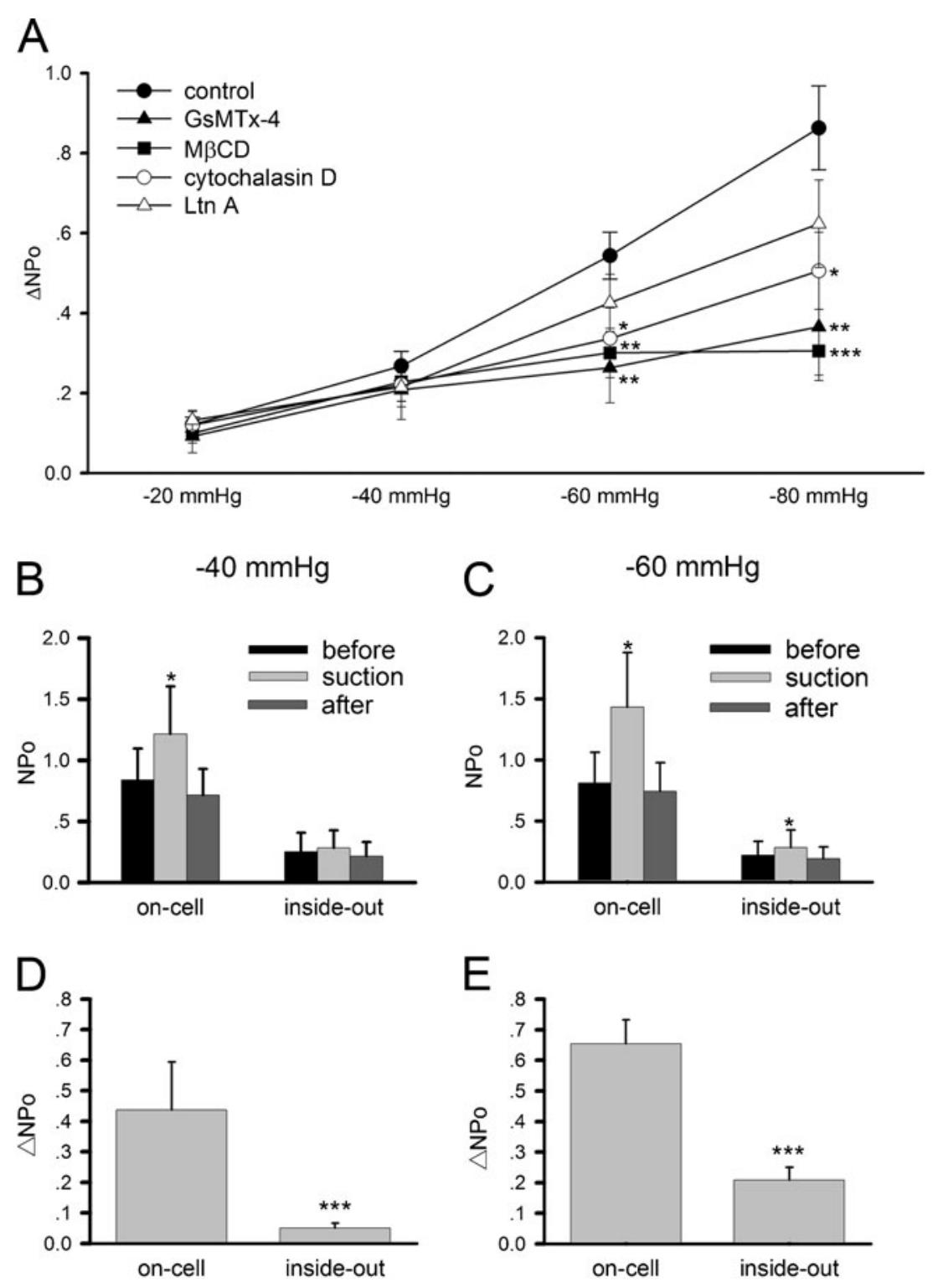

The function of rapsyn in AChR mechanosensitivity

By comparing data from Xenopus and C2C12 muscle cells (Fig. 1b, c, e, f) with those from HEK293T cells (Fig. 2b, c), one can see that the mechanosensitivity of endogenous AChRs in muscle was less than that of exogenous ones expressed in heterologous cells. A major difference between these cell types that could have a bearing on AChRs is the association of AChRs with rapsyn, which is an AChRbinding protein expressed mainly by muscle cells [4]. Rapsyn is essential for AChR clustering at the NMJ and is generally thought to mediate the receptor's interaction with the cytoskeleton. To examine a potential role of rapsyn in regulating AChR's mechanosensitivity, it was co-expressed with the receptor subunits in HEK293T cells. As shown in Fig. 5a, b, membrane stretching through pipette negative pressure still increased AChR activity. However, this increment was significantly less than that shown by receptors expressed without rapsyn (Fig. 2b; note the reduced scale of $y$-axis in Fig. 5 b relative to Figs. 1 and 2). This change becomes clearer when $\Delta$ NPo values are compared: rapsyn potently suppressed $\Delta \mathrm{NPo}$ throughout the range of negative pressures tested (Fig. 5c).

Additional experiments showed the specific effect of rapsyn's association with AChR on the channel's mechanosensitivity. Rapsyn interacts with AChRs via its coiled coil domain [37, 38]. Deletion of this domain (in the mutant rapsyn-M) dramatically reduced rapsyn's inhibitory effect on AChR's mechanosensitivity (Fig. 5c), suggesting that rapsyn binding to $\mathrm{AChR}$ effectively suppresses the influence of mechanical stimuli on the receptor's activity.

Co-expression of wild-type rapsyn leads to AChR cluster formation in heterologous cells $[15,36]$, which was also observed in this study (NCP and HBP, unpublished 
A

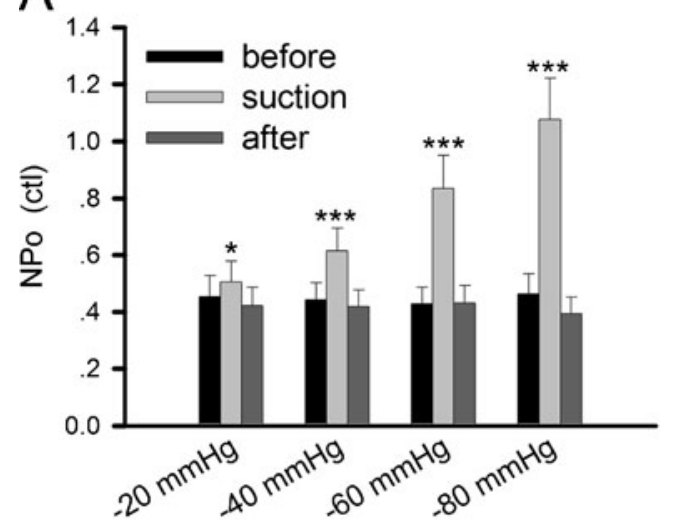

B
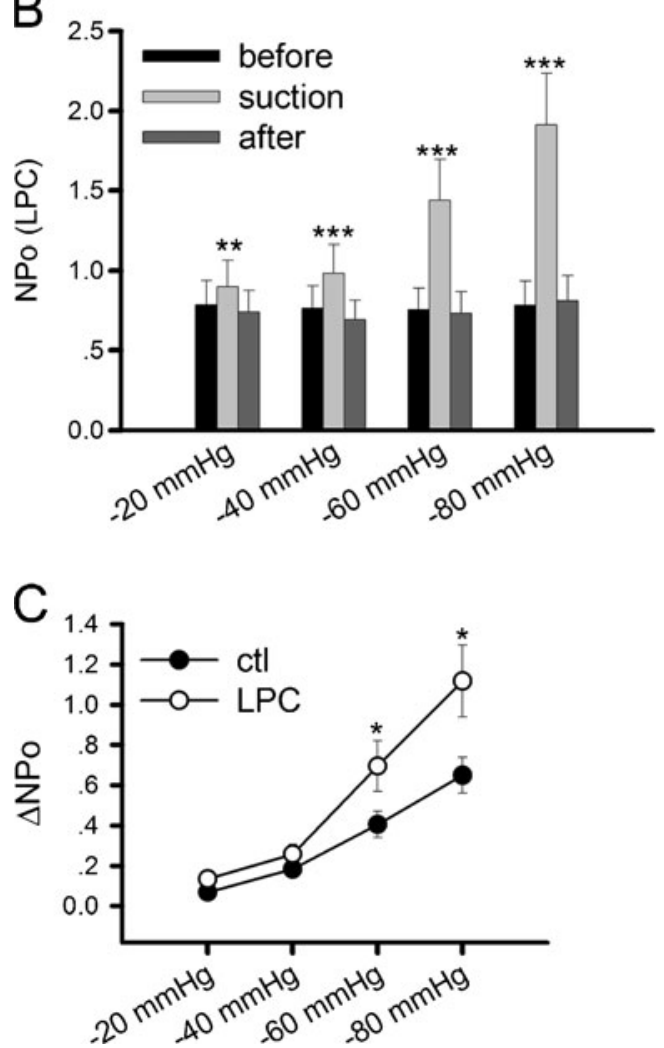

Fig. 4 Effect of LPC on AChR mechanosensitivity. AChR-expressing HEK 293 cells were pretreated with LPC for $10 \mathrm{~min}$ before patch-clamp recording. a Channel activity NPo of AChRs before (black), during (gray), and after (dark gray) negative pressure application in control cultures; $n=16$ patches. b NPo of LPC-treated AChRs; $n=16$ patches. $\mathbf{c}$ The difference of NPo for control and LPC-treated AChRs at different negative pressure

observations). This clustering lowered the density of diffuse AChRs at the cell surface, as shown by current recording under whole-cell mode (Supplemental Fig. S3). Because of this reduction in diffuse AChR site density, we also plotted the ratios of NPo under each negative pressure to that under normal pressure (before suction) and normalized them (Fig. 6). By calculating this NPo ratio, we can rule out the possibility that reduction in channel activity $(\mathrm{NPo})$ is due to a decrease in surface AChR number $(\mathrm{N})$. As with the $\triangle \mathrm{NPo}$
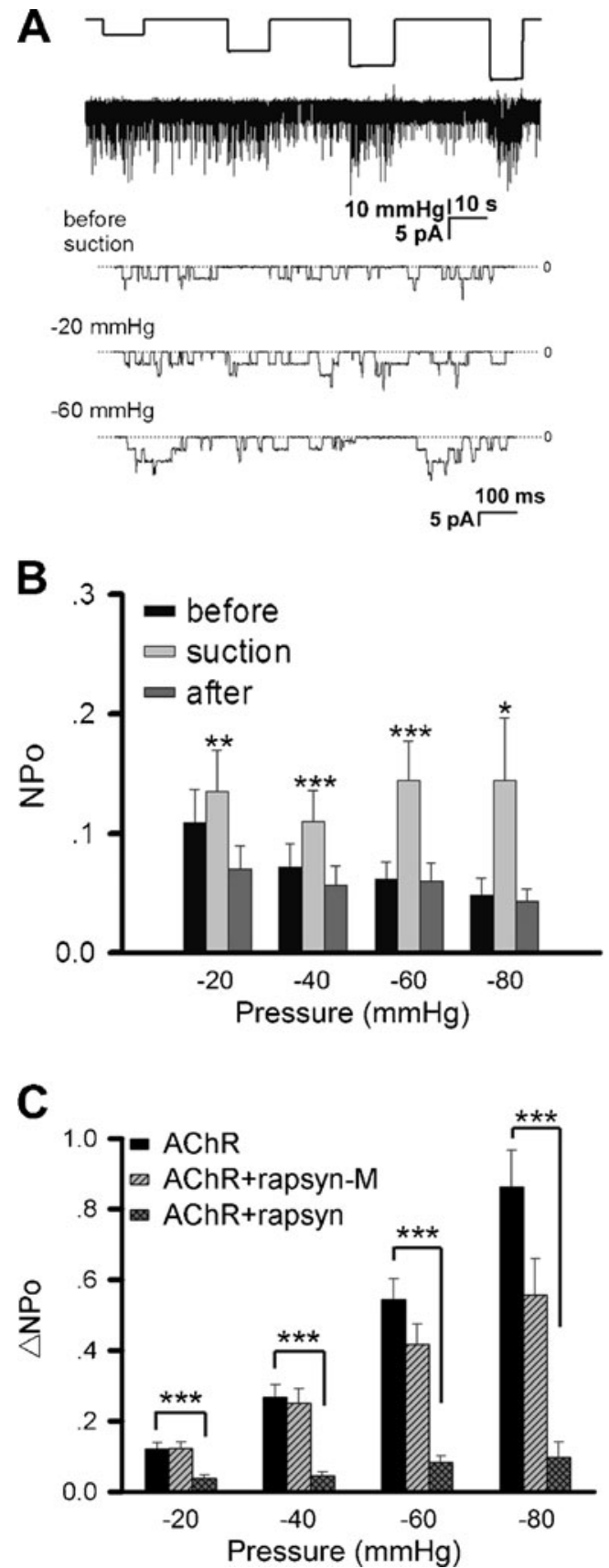

Fig. 5 The effect of rapsyn on AChR mechanosensitivity. HEK293T cells were transfected with cDNAs encoding AChR subunits plus one encoding rapsyn. a Sample current recording of AChRs under different pipette negative pressures in the cell-attached mode; pipette holding potential $+70 \mathrm{mV}$ with $0.5 \mu \mathrm{M}$ ACh. b NPo of ACh-induced singlechannel currents from rapsyn-co-expressing cells before (black), during (gray), and after (dark gray) negative pressure application. Note the reduced scale of $y$-axis compared to Figs. 1 and 2. $N=21,18,11,6$ patches for $-20,-40,-60,-80 \mathrm{mmHg}$, respectively. $\mathbf{c} \Delta \mathrm{NPo}$ values of AChRs expressed alone, with rapsyn or with mutant rapsyn lacking the AChR-binding domain (rapsyn-M). Data from 18 to 26 patches were pooled. ${ }^{*} p<0.05 ; * * p<0.01 ; * * * p<0.001$ 
plot in Fig. 5c, here again rapsyn's effect on reducing AChR's mechanosensitivity was obvious (Fig. 6) even though rapsyn expression also lowered the density of diffuse receptors.

To further understand the interplay between rapsyn and the cytoskeleton in mediating the mechanosensitivity of AChRs, the effect of cytochalasin D on AChR and rapsyn co-expressing cells was studied. Cytochalasin D treatment reduced AChR's mechanosensitivity in the absence of rapsyn (Fig. 3a). However, in rapsyn co-expressing cells, cytoskeletal disruption caused an increase in AChR opening induced by membrane stretch, although the level was still lower than that seen in cells expressing AChRs alone (Fig. 6). Similar effects of cytochalasin D were also observed in $\mathrm{C} 2 \mathrm{C} 12$ cells which endogenously express rapsyn (Supplemental Fig. S4). These data suggest that rapsyn, through its binding to AChRs, suppresses the receptor's mechanosensitivity. And though the exact molecular mechanism of this suppression is not known, the integrity of the cortical F-actin cytoskeleton appears to be critical for rapsyn's ability to perform this function effectively.

\section{Discussion}

In this study, the mechanosensitivity of nicotinic AChR in the skeletal muscle was characterized for the first time. This property was manifested as membrane stretch-induced increase in the channel activity (but not channel conductance) after ligand binding to the receptor. Unlike other MSCs in muscle membrane that respond to membrane stretch alone

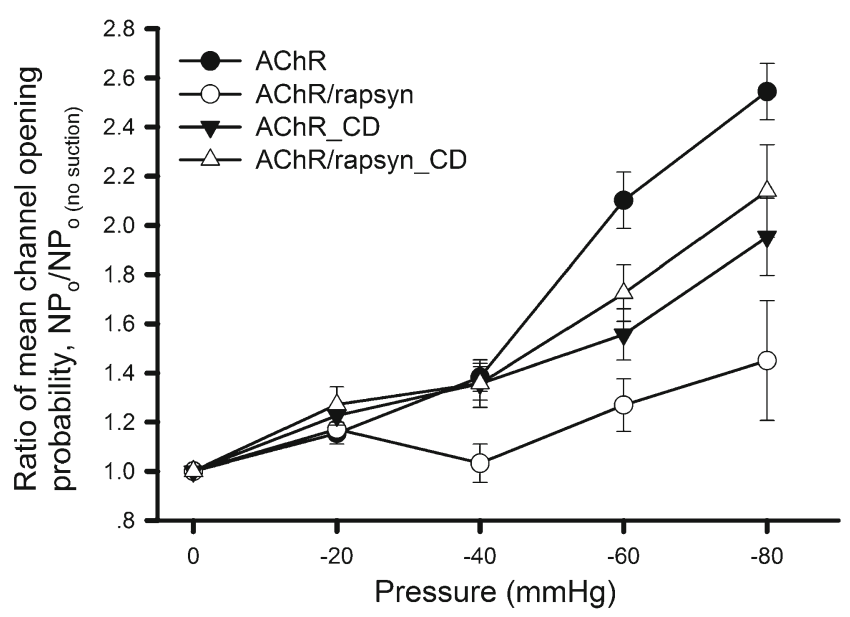

Fig. 6 Ratio of NPo under different experimental conditions. HEK293T cells expressing AChRs alone or together with rapsyn were recorded in the presence or absence of cytochalasin $\mathrm{D}(C D ; 2 \mu \mathrm{M}$, 30 min pre-incubation). The NPo values obtained at each negative pressure were divided by the respective basal NPo. Data from more than 20 patches were pooled for each point. Student's $t$ test showed no significant difference between the results of AChR_CD and AChR/ rapsyn_CD $(p>0.2)$
$[13,14,19]$, mechanical stimulus only modulated ligandactivated AChR opening. Mechanosensitivity was exhibited by embryonic $\left(\alpha_{2} \beta \delta \gamma\right)$ as well as adult $\left(\alpha_{2} \beta \delta \varepsilon\right)$ AChRs. Since this property was manifested by endogenous AChRs in muscle cells and exogenous ones expressed in HEK293T, the mechanosensitivity is a general property of this channel and not unique to its muscle membrane environment.

AChR's mechanosensitivity resembles that of another ligand-gated channel, the NMDA receptor. Membrane stretching has been reported to increase the NMDA response of cultured embryonic mouse neurons [32], where mechanical force only modulates ligand-induced activation and does not by itself cause channel opening, much as with AChRs here. The mechanosensitive property seems unique to NMDA receptors, for it was not observed among other receptors in mouse neurons, including kainate, glycine, and GABA receptors [32]. In another study, purified NR1a and NR2A subunits of the NMDA receptor were reconstituted into liposomes, and it was found that only the lipid bilayer was involved in the mechanosensitivity [23]. For the AChR, both membrane lipids and the cytoskeleton were found to be involved in generating its mechanosensitivity through studies conducted in HEK293T cells as reported here. Interestingly, the co-expression of the receptor-associated protein rapsyn can counteract the effect of the mechanical force.

AChR's response to mechanical stimuli, like that of other MSCs, was blocked by the spider toxin GsMTx-4 [6] and was detected in both Xenopus and mammalian (C2C12) muscle cells in this study. The mechanosensitivity of C2C12 receptors was smaller than their Xenopus primary muscle counterparts. AChR's channel open time in chick myotubes, however, is apparently not affected by membrane stretching [19]. Thus, there could be a species-dependent difference in AChR mechanosensitivity. Moreover, in preliminary studies using cortical neurons isolated from E18 rat brain, we recorded no significant enhancement of ACh single-channel currents upon applying negative pressure through the patch-clamp pipette (Supplemental Fig. S5). We also failed to observe mechanosensitivity when $\alpha 7$ nicotinic receptors were expressed in HEK293T cells together with the ric 3 gene (to increase the surface expression and assembly of this receptor in heterologous cells) $[49,50]$ (NCP and HBP, unpublished observations). Thus, for nicotinic receptors, mechanosensitivity appears to be specific to the skeletal muscle type. Interestingly, AChR's mechanosensitivity was not dependent specifically on its native environment in Xenopus myotomal muscle cells in primary culture or in $\mathrm{C} 2 \mathrm{C} 12$ myotubes; it was also observed when receptors were heterologously expressed in HEK293T cells.

In the muscle, the membrane is an important mediator of force transmission from sarcomeres to the myotendinous junction during contractile activity [33, 45]. Although we do not know the membrane tension generated during 
muscular activity, previous studies have shown that the intramuscular fluid pressure (IMP) reaches $270 \mathrm{mmHg}$ in the soleus muscle in humans while running and under prolonged submaximal contraction, IMP can reach a level of $\sim 570 \mathrm{mmHg}[3,41]$. The mechanical tension generated at the cell membrane of the skeletal muscle can be expected to have a significant impact on normal synaptic transmission at the NMJ, where most AChRs are concentrated. Activated AChRs allow the non-specific passage of monovalent and divalent cations, including calcium. The enhanced channel opening caused by membrane tension could thus increase calcium ion influx at the endplate. This may lead to deleterious consequences due to calcium-mediated myopathy at the NMJ that bears similarity to slow-channel myasthenic syndrome $[10,25,47]$. In this regard, rapsyn's restriction of AChR mechanosensitivity in muscle could be a built-in mechanism for protecting the integrity of the $\mathrm{NMJ}$ and the muscle fiber.

Rapsyn associates with the cytoplasmic domain of AChR subunits and is essential for the assembly of the receptors into high-density postsynaptic clusters $[5,28]$. During development, the ratio of rapsyn to $\mathrm{AChR}$ increases, and this has been shown to contribute to the stability of AChRs at the endplate $[17,18]$. Our current study suggests that this stabilization is accomplished in part through rapsyn's ability to lower AChR's mechanosensitivity. Thus, in addition to its well-known role in AChR clustering, a new function of rapsyn is now described - of counteracting the intrinsic AChR property of enhanced opening under membrane tension. Intriguingly, disruption of F-actin compromised the resistance of AChRs to mechanical force conferred by rapsyn co-expression. Thus, rapsyn bound to cytoplasmic domains of AChR subunits may stabilize the receptor by consolidating its interaction with the cytoskeleton. The high-density clustering of AChRs at the postsynaptic membrane is likely an important mechanism to shield them from tension by itself as the lipid microdomain surrounding the receptors is more rigid than the surrounding area. Thus, rapsyn is involved in regulating AChRs' mechanosensitivity from both the aspect of cluster formation and in linking individual receptors to the cytoskeleton.

Three broad mechanisms have been proposed to account for the stretch sensitivity of membrane ion channels, referred to as bilayer, tethered, and hybrid models [21]. The bilayer model depicts that mechanical forces are conveyed to the channel via the lipid membrane. In the tethered model, the channel is considered to be linked directly to extracellular or cytoskeletal proteins that act as a gating mechanism to mediate the effect of the mechanical force. The hybrid model combines both features. Based on studies using two F-actin disrupting agents (LtnA and cytochalasin D), we conclude that mechanosensitivity of AChRs is dependent on the intactness of the cytoskeleton. On one hand, the stretchinduced response of AChRs was suppressed by $\mathrm{M} \beta \mathrm{CD}$ that depletes cholesterol, a known determinant in the viscoelastic property of the membrane [30, 39]. On the other hand, LPC causes an enhancement of AChR's mechanosensitivity. This conical phospholipid causes changes in membrane curvature when intercalated into one side of the lipid bilayer, and this has been shown to increase the opening of the bacterial mechanosensitive channel [35]. Thus, our M $\beta C D$ and LPC results suggest that the protein-lipid interface is also involved in AChR's mechanosensitivity. Together, these data therefore suggest that both the cortical cytoskeleton and the membrane lipid environment participate in transmitting the
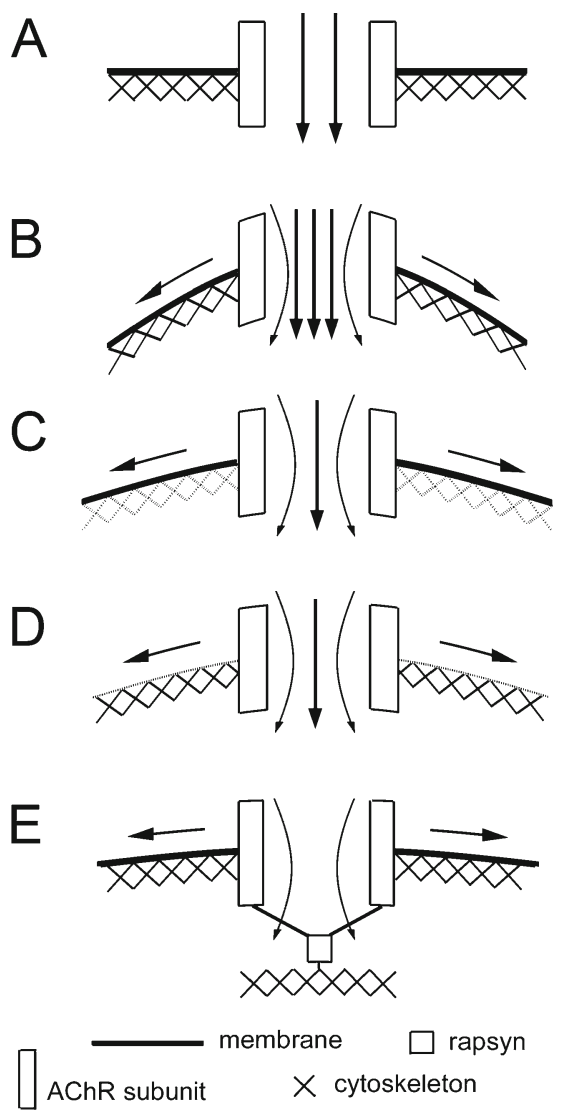

Fig. 7 A model on the regulation of AChR mechanosensitivity by the membrane and the cytoskeleton. a Channel opening under zero negative pressure. As a transmembrane molecule, AChR's gating property can potentially be influenced by the mechanical properties of the membrane and the cytoskeleton. b Under negative pressure application through the recording pipette, the tension generated along the plane of the membrane causes increased channel activity. c Disruption of the cortical F-actin cytoskeleton by latrunculin A of cytochalasin D reduces the influence of the membrane stretch force on the receptor, leading to a decrease in channel activity. $\mathbf{d}$ Membrane lipid modification that reduces its stiffness such as cholesterol depletion by $\mathrm{M} \beta \mathrm{CD}$ also reduces the stretch force experienced by the receptor and the mechanosensitivity. e Rapsyn, through its interaction with AChR subunits, anchors the receptor complex to the cytoskeleton to lessen the impact of membrane stress on its gating, thus reducing the mechanosensitivity 
tensile stress force in the plane of the membrane to AChRs to enhance ligand-induced channel opening. A model depicting the control of AChR's mechanosensitivity is shown in Fig. 7.

The elucidation of AChR's mechanosensitive property opens up a new way in understanding the channel's gating mechanisms, which, coupled with AChR's well characterized structure-function relationship, should yield further insights into this ligand-gated channel's behavior and regulation in normal and diseased states.

Acknowledgments We are grateful for the technical and scientific advice of Dr. Pingbo Huang (HKUST) and his colleagues Drs. Dong Wang and Wei Zhang. We also thank Drs. Stanley Froehner, Jean Cartaud, and Veit Witzemann for generously sharing their cDNAs with us. This study was supported by RGC grants HKUST6417/06 M, 662108 and 662311, and by HKUST intramural grant RPC11SC10.

Open Access This article is distributed under the terms of the Creative Commons Attribution License which permits any use, distribution, and reproduction in any medium, provided the original author(s) and the source are credited.

\section{References}

1. AL-Shawaf E, Tumova S, Naylor J, Majeed Y, Li J, Beech DJ (2011) GVI phospholipase A2 role in the stimulatory effect of sphingosine-1-phosphate on TRPC5 cationic channels. Cell Calcium 50:343-350

2. Arnadottir J, Chalfie M (2010) Eukaryotic mechanosensitive channels. Annu Rev Biophys 39:111-137

3. Ballard RE, Watenpaugh DE, Breit GA, Murthy G, Holley DC, Hargens AR (1998) Leg intramuscular pressures during locomotion in humans. J Appl Physiol 84:1976-1981

4. Banks GB, Fuhrer C, Adams ME, Froehner SC (2003) The postsynaptic submembrane machinery at the neuromuscular junction: requirement for rapsyn and the utrophin/dystrophin-associated complex. J Neurocytol 32:709-726

5. Borges LS, Yechikhov S, Lee YI, Rudell JB, Friese MB, Burden SJ, Ferns MJ (2008) Identification of a motif in the acetylcholine receptor beta subunit whose phosphorylation regulates rapsyn association and postsynaptic receptor localization. J Neurosci 28:11468-11476

6. Bowman CL, Gottlieb PA, Suchyna TM, Murphy YK, Sachs F (2007) Mechanosensitive ion channels and the peptide inhibitor GsMTx-4: history, properties, mechanisms and pharmacology. Toxicon 49:249-270

7. Casella JF, Flanagan MD, Lin S (1981) Cytochalasin D inhibits actin polymerization and induces depolymerization of actin filaments formed during platelet shape change. Nature 293:302305

8. Christian AE, Haynes MP, Phillips MC, Rothblat GH (1997) Use of cyclodextrins for manipulating cellular cholesterol content. J Lipid Res 38:2264-2272

9. Coue M, Brenner SL, Spector I, Korn ED (1987) Inhibition of actin polymerization by latrunculin A. FEBS Lett 213:316-318

10. Engel AG, Shen XM, Selcen D, Sine SM (2010) What have we learned from the congenital myasthenic syndromes. J Mol Neurosci $40: 143-153$
11. Engel AG, Sine SM (2005) Current understanding of congenital myasthenic syndromes. Curr Opin Pharmacol 5:308-321

12. Fertuck HC, Salpeter MM (1974) Localization of acetylcholine receptor by $125 \mathrm{I}$-labeled alpha-bungarotoxin binding at mouse motor endplates. Proc Natl Acad Sci U S A 71:1376-1378

13. Franco-Obregon A Jr, Lansman JB (1994) Mechanosensitive ion channels in skeletal muscle from normal and dystrophic mice. J Physiol 481:299-309

14. Franco-Obregon A, Lansman JB (2002) Changes in mechanosensitive channel gating following mechanical stimulation in skeletal muscle myotubes from the mdx mouse. J Physiol 539:391-407

15. Froehner SC, Luetje CW, Scotland PB, Patrick J (1990) The postsynaptic $43 \mathrm{~K}$ protein clusters muscle nicotinic acetylcholine receptors in Xenopus oocytes. Neuron 5:403-410

16. Gautam M, Noakes PG, Mudd J, Nichol M, Chu GC, Sanes JR, Merlie JP (1995) Failure of postsynaptic specialization to develop at neuromuscular junctions of rapsyn-deficient mice. Nature 377:232-236

17. Gervasio OL, Armson PF, Phillips WD (2007) Developmental increase in the amount of rapsyn per acetylcholine receptor promotes postsynaptic receptor packing and stability. Dev Biol 305:262-275

18. Gervasio OL, Phillips WD (2005) Increased ratio of rapsyn to ACh receptor stabilizes postsynaptic receptors at the mouse neuromuscular synapse. J Physiol 562:673-685

19. Guharay F, Sachs F (1984) Stretch-activated single ion channel currents in tissue-cultured embryonic chick skeletal muscle. J Physiol 352:685-701

20. Hackney CM, Furness DN (1995) Mechanotransduction in vertebrate hair cells: structure and function of the stereociliary bundle. Am J Physiol 268:C1-C13

21. Hamill OP (2006) Twenty odd years of stretch-sensitive channels. Pflugers Arch 453:333-351

22. Hamill OP, Martinac B (2001) Molecular basis of mechanotransduction in living cells. Physiol Rev 81:685-740

23. Kloda A, Lua L, Hall R, Adams DJ, Martinac B (2007) Liposome reconstitution and modulation of recombinant $N$-methyl-D-aspartate receptor channels by membrane stretch. Proc Natl Acad Sci U S A 104:1540-1545

24. Kung C, Martinac B, Sukharev S (2010) Mechanosensitive channels in microbes. Annu Rev Microbiol 64:313-329

25. Leonard JP, Salpeter MM (1979) Agonist-induced myopathy at the neuromuscular junction is mediated by calcium. J Cell Biol 82:811-819

26. Leonard RJ, Nakajima S, Carlson CG (1988) Early development of two types of nicotinic acetylcholine receptors. J Neurosci 8:40384048

27. Lindstrom JM (2000) Acetylcholine receptors and myasthenia. Muscle Nerve 23:453-477

28. Maimone MM, Merlie JP (1993) Interaction of the $43 \mathrm{kd}$ postsynaptic protein with all subunits of the muscle nicotinic acetylcholine receptor. Neuron 11:53-66

29. Mishina M, Takai T, Imoto K, Noda M, Takahashi T, Numa S, Methfessel C, Sakmann B (1986) Molecular distinction between fetal and adult forms of muscle acetylcholine receptor. Nature 321:406-411

30. Norman LL, Oetama RJ, Dembo M, Byfield F, Hammer DA, Levitan I, Aranda-Espinoza H (2010) Modification of cellular cholesterol content affects traction force, adhesion and cell spreading. Cell Mol Bioeng 3:151-162

31. Ohtani Y, Irie T, Uekama K, Fukunaga K, Pitha J (1989) Differential effects of alpha-, beta- and gamma-cyclodextrins on human erythrocytes. Eur J Biochem 186:17-22

32. Paoletti P, Ascher P (1994) Mechanosensitivity of NMDA receptors in cultured mouse central neurons. Neuron 13:645655 
33. Patel TJ, Lieber RL (1997) Force transmission in skeletal muscle: from actomyosin to external tendons. Exerc Sport Sci Rev 25:321363

34. Peng HB, Baker LP, Chen Q (1991) Tissue culture of Xenopus neurons and muscle cells as a model for studying synaptic induction. In: Kay BK, Peng HB (eds) Xenopus laevis: practical uses in cell and molecular biology. Methods in Cell Biology, vol 36. Academic Press, San Diego, pp 511-526

35. Perozo E, Kloda A, Cortes DM, Martinac B (2002) Physical principles underlying the transduction of bilayer deformation forces during mechanosensitive channel gating. Nat Struct Biol 9:696-703

36. Phillips WD, Kopta C, Blount P, Gardner PD, Steinbach JH, Merlie JP (1991) ACh receptor-rich membrane domains organized in fibroblasts by recombinant 43 -kildalton protein. Science 251:568-570

37. Ramarao MK, Bianchetta MJ, Lanken J, Cohen JB (2001) Role of rapsyn tetratricopeptide repeat and coiled-coil domains in selfassociation and nicotinic acetylcholine receptor clustering. J Biol Chem 276:7475-7483

38. Ramarao MK, Cohen JB (1998) Mechanism of nicotinic acetylcholine receptor cluster formation by rapsyn. Proc Natl Acad Sci U S A 95:4007-4012

39. Renner M, Choquet D, Triller A (2009) Control of the postsynaptic membrane viscosity. J Neurosci 29:2926-2937

40. Schwander M, Kachar B, Muller U (2010) Review series: the cell biology of hearing. J Cell Biol 190:9-20

41. Sejersted OM, Hargens AR, Kardel KR, Blom P, Jensen O, Hermansen L (1984) Intramuscular fluid pressure during isometric contraction of human skeletal muscle. J Appl Physiol $56: 287-295$
42. Spector I, Shochet NR, Kashman Y, Groweiss A (1983) Latrunculins: novel marine toxins that disrupt microfilament organization in cultured cells. Science 219:493-495

43. Suchyna TM, Johnson JH, Hamer K, Leykam JF, Gage DA, Clemo HF, Baumgarten CM, Sachs F (2000) Identification of a peptide toxin from Grammostola spatulata spider venom that blocks cation-selective stretch-activated channels. J Gen Physiol 115:583-598

44. Thomas P, Smart TG (2005) HEK293 cell line: a vehicle for the expression of recombinant proteins. J Pharmacol Toxicol Methods $51: 187-200$

45. Trotter JA (1993) Functional morphology of force transmission in skeletal muscle. A brief review. Acta Anat (Basel) 146:205-222

46. Vasquez V, Sotomayor M, Cordero-Morales J, Schulten K, Perozo E (2008) A structural mechanism for MscS gating in lipid bilayers. Science 321:1210-1214

47. Vohra BP, Groshong JS, Maselli RA, Verity MA, Wollmann RL, Gomez CM (2004) Focal caspase activation underlies the endplate myopathy in slow-channel syndrome. Ann Neurol 55:347-352

48. Vollrath MA, Kwan KY, Corey DP (2007) The micromachinery of mechanotransduction in hair cells. Annu Rev Neurosci 30:339-365

49. Wang Y, Yao Y, Tang XQ, Wang ZZ (2009) Mouse RIC-3, an endoplasmic reticulum chaperone, promotes assembly of the alpha7 acetylcholine receptor through a cytoplasmic coiled-coil domain. J Neurosci 29:12625-12635

50. Williams ME, Burton B, Urrutia A, Shcherbatko A, Chavez-Noriega LE, Cohen CJ, Aiyar J (2005) Ric-3 promotes functional expression of the nicotinic acetylcholine receptor alpha7 subunit in mammalian cells. J Biol Chem 280:1257-1263 